University of Nebraska - Lincoln

DigitalCommons@University of Nebraska - Lincoln

Educational Psychology Papers and

Publications

Educational Psychology, Department of

January 1993

\title{
Schoolwide Social Skills Training: Providing Preventive Services to Students At-Risk
}

Robert N. Jones

Primary Children's Medical Center, Salt Lake, Utah

Susan M. Sheridan

University of Nebraska-Lincoln, ssheridan2@unl.edu

Wayne R. Binns

Midvale Elementary School, Jordan School District, Sandy, Utah

Follow this and additional works at: https://digitalcommons.unl.edu/edpsychpapers

Part of the Educational Psychology Commons

Jones, Robert N.; Sheridan, Susan M.; and Binns, Wayne R., "Schoolwide Social Skills Training: Providing Preventive Services to Students At-Risk" (1993). Educational Psychology Papers and Publications. 69. https://digitalcommons.unl.edu/edpsychpapers/69

This Article is brought to you for free and open access by the Educational Psychology, Department of at DigitalCommons@University of Nebraska - Lincoln. It has been accepted for inclusion in Educational Psychology Papers and Publications by an authorized administrator of DigitalCommons@University of Nebraska - Lincoln. 
Published in School Psychology Quarterly, 8:1 (1993), pp. 57-80.

Copyright (C) 1993 American Psychological Association. Used by permission. "This article may not exactly replicate the final version published in the APA journal. It is not the

copy of record." http://www.apa.org/journals/spq/

Accepted for publication November 8, 1992.

Action Editor for School Psychology Quarterly: Joseph C. Witt.

\title{
Schoolwide Social Skills Training: Providing Preventive Services to Students At-Risk
}

\author{
Robert N. Jones, Primary Children's Medical Center, Salt Lake, Utah \\ Susan M. Sheridan, University of Utah \\ Wayne R. Binns, Midvale Elementary School, Jordan School District, Sandy, Utah
}

\begin{abstract}
This paper reports a schoolwide social skills assessment and training model including a two-gate student identification procedure (i.e., in-class social skills training for all students and small group intensive training for at-risk target students). The model is directed at reducing future serious problems by addressing identified difficulties early (i.e., through secondary prevention procedures). Specific model objectives are to (a) utilize a comprehensive, multigate procedure to identify students at risk; (b) implement schoolwide training procedures to teach a number of important prosocial skills identified by teachers; (c) treat a subgroup of target subjects considered at highest risk for developing pervasive social problems; and (d) implement procedures to encourage the transfer and generalization of all students' skills across untrained stimuli, settings, and situations. Of central importance is the inclusion of all individuals in the school building (i.e., teachers, aides, administrators, support staff, and office personnel) in training and generalization activities.
\end{abstract}

...social-emotional development seems to have more impact than cognitive development on determining success or failure, adaptation or maladaptation in school, as well as society at large. (Black, Downs, Bastien, Brown, \& Wells, 1987; p. vi)

There is general agreement that at least $12 \%$, or 7.5 million of the nation's children suffer from emotional or other problems that warrant mental health services (Dougherty, 1988). There are literally thousands of children at serious risk of developing mental health problems. These include children living in poverty, in alcoholic families, in abusive households, in single-parent families, and in

Reprints can be obtained from Robert Jones, Inpatient Psychiatry-East, Primary Children's Medical Center, 100 North Medical Drive, Salt Lake, UT, 84113-1100. Inquiries about uncommercial forms should be directed to the authors by sending a self-addressed and stamped envelope. 
other potentially damaging situations. However, only $20 \%$ to $30 \%$ of children in need receive the appropriate mental health services (Dougherty, 1988).

The likelihood of children at risk developing behavioral or emotional disorders increases directly as they feel greater levels of stress and as they possess an increasing number of vulnerabilities (Elias \& Branden, 1988). However, the degree to which one possesses coping skills, adequate social supports, and positive self-esteem can offset some of the risks posed by life stressors. Schoolwide programs designed to teach social problem-solving skills are recommended to improve one's coping abilities and offset various risk factors experienced by children at risk (Elias \& Branden, 1988).

Unequivocally, there is a need to develop prevention or early intervention programs to address the social and mental health needs of youth. The objective of secondary prevention programs is to address mental health problems before they exacerbate and have a lasting negative effect on children's development. The role of schools in secondary prevention has been demonstrated (Cowen, Pederson, Babigan, Izzo, \& Trost, 1973) under the assumption that "competence and mental health are inseparable ... Teaching children interpersonal skills .. . [is] as essential as teaching reading, writing, arithmetic, and science" (DeLeon, 1986, p.39). Successful schoolwide programs targeting areas of drug awareness (Forman\& Linney, 1988), social skills (Cartledge \& Milburn, 1986), and coping skills (Botvin, 1983) have been documented.

Although the importance of social skills training programs has been recognized by practitioners and researchers, various problems have been noted in the manner in which social skills programs are implemented in schools. First, the identification of which specific social skills to target in training is often subjective, and skills are commonly selected with no empirical justification of their need for identified students. Second, procedures used in practice (e.g., modeling, coaching) are typically selected arbitrarily, with little individualization based on the nature of student deficits (i.e., performance or skill deficits). Third, most social skills programs are designed to be used with small groups of students. Schoolwide programs that impact a large population of high risk students are rare. Fourth, the vast majority of programs delineate procedures to be used in the training setting only. Little or no attention is given to generalization of skills in the natural environment, and individuals within target students' ecological settings (e.g., teachers and other school personnel) are generally not included in training. Finally, parents are typically not adequately informed of the skills taught to their students or how they might reinforce the efforts of school personnel.

The purposes of this article are threefold. First, various assessment methods and treatment procedures commonly found in the social skills literature will be reviewed. Much of the substantive information in this regard is based on reviews by Gresham (1981) and Elliott, Sheridan, and Gresham (1989). Second, a number of "best practices" in social skills assessment and treatment will be identified (i.e., practices with sound empirical evidence attesting to their validity) that 
also are practical and meaningful in applied settings. Finally, these empirically based best practices will be integrated into a comprehensive schoolwide social skills training model. The model is designed for elementary aged students who are considered at risk for developing serious psychological or social problems.

\section{REVIEW OF RELEVANT LITERATURE}

Social skills are critical in the ability to interact with, adapt to, and function within the environment. Research has indicated that social skill deficits in childhood, if left untreated, are relatively stable over time, are related to poor academic performance, and may be predictive of adjustment problems and serious psychopathology later in life (Coie \& Dodge, 1983; Cowen et al., 1973; Parker \& Asher, 1987). In brief, children who demonstrate social difficulties experience both short- and long-term negative consequences, and these consequences seem to be precursors of more serious problems in adolescence and adulthood.

\section{Assessing Social Skills Deficits}

A number of assessment strategies have been found to be important in obtaining a comprehensive evaluation of a student's social behaviors. These strategies include direct observations across settings and situations, parent and teacher rating scales, sociometric ratings or nominations, and self-reports. Table 1 provides a summary of these procedures.

Direct Observations. Direct observations are important in social skills assessment for a number of reasons. They provide a direct measure of students' social interactions in applied settings, allow for a functional analysis of the student's behaviors in a social context, and provide an opportunity to observe the reactions of peers. Likewise, they allow for a social comparison with a matched peer, which will be important in determining the social validity of the observation and of a chosen treatment (Kazdin, 1977). As with other assessment methods, direct observations should occur across settings. Parents, teachers, and school aides and staff can be trained to conduct simple observations to obtain consistent and ongoing behavioral data over contextual bases. There are many observational systems available, but whatever method is used, specific target behaviors should be assessed directly.

Children at risk for developing social-emotional problems may demonstrate high rates of aggression, low rates of peer interaction, inappropriate responses within a social context, or some combination of these. Whereas high rates of aggression appear to be most closely related to teachers', parents', and peers' evaluations (and are thus appropriate for targeting in direct observations), simple interaction rates do not appear to be sufficient in determining qualitative aspects of social behaviors (Asher, Markell, \& Hymel, 1981). The specific nature, function, and direction of social behaviors should be assessed in direct observations. Likewise, direct assessments of the social environment should be conducted to ascertain competence across various interpersonal conditions. 


\section{Table 1. Summary of Social Skills Assessment Methods}

1. Teacher rating of social skills

A. Estimate frequency of behaviors

B. Estimate behavior's importance to teacher

C. Estimate skill and performance deficits

D. Provide guideline for teacher interview and direct observations

E. Evaluate social validity of intervention

2. Parent ratings of social skills

A. Estimate social skills deficits across settings

B. Estimate parent's perceived importance of social behaviors

C. Provide guideline for parent interview

D. Evaluate social validity of intervention

3. Sociometrics

A. Measure social preference and social impact

B. Obtain sociometric status classification (rejected, neglected, or controversial)

C. Evaluate change in social perceptions as a function of intervention

4. Self-report of social skills

A. Obtain child's perception of social behavior

B. Consider child ratings in target selection

C. Evaluate child perceptions regarding treatment effectiveness

5. Parent-Teacher interviews

A. Further delineate and specify target behaviors

B. Explicate consultation goals and behavioral objectives

C. Provide functional analysis of behavior in specific situations

D. Identify setting events and conditional factors surrounding behaviors

E. Assess treatment preferences and acceptability to consultees

F. Develop cross-setting interventions to facilitate consistency and generalization

G. Evaluate perceptions regarding treatment effectiveness

6. Direct observations

A. Provide functional analysis of behavior

B. Obtain direct measure of behavior in applied settings

C. Observe qualitative aspects of social behavior, such as nature, function, and peer reactions

D. Allow social comparison of target child with matched peer

7. Child interview

A. Obtain child's perception of social behavior

B. Consider child's input in selecting target behavior, goals of consultation, and intervention strategies

C. Evaluate child perceptions regarding treatment effectiveness

Reproduced with modifications from: Elliott, S. N., Sheridan, S. M., \& Gresham, F. M. (1989). Assessing and treating social skills deficits: A case study for the scientist-practitioner. Journal of School Psychology, 27, 197-222.

Rating Scales. Rating scale assessments are helpful in obtaining objective data regarding important components of a student's social skills from a variety of sources. Rating scales can provide an estimate of the frequency of behaviors, a tentative estimate of skill and performance deficits, and a guideline for interviews and direct observations across settings (Elliott et al., 1989). Rating scale data can be obtained from at least three sources: adults, peers, and the student himself or herself. 
Unfortunately, there are currently few formal social skills rating scales that demonstrate adequate reliability, validity, and practicality. Two exceptions are the Walker-McConnell Scale of Social Competence and School Adjustment (Walker \& McConnell, 1988) and the Social Skills Rating System (SSRS; Gresham \& Elliott, 1990), which provide reliable and functional data on a student's social behaviors. For example, the SSRS provides information on both the frequency and importance of various social behaviors. It is very skill-based (e.g., "Invites friends over to play"), and offers a link to intervention (Elliott \&Gresham, 1992). There are separate forms for parents, teachers, and students, which provide important information across sources and settings. A great deal of psychometric support for the SSRS is available, documenting its internal consistency, test-retest reliability, factorial, construct, concurrent, and discriminant validity (Clark, Gresham, \& Elliott, 1985; Gresham, Elliott, \& Black, 1987; Gresham \& Elliott, 1990). The inclusion of adult rating scales in the assessment of social competence in children is based on the assumption that adults who know the child well are able to interpret and understand the child's social interactions with peers. However, a large portion of the peer culture is not accessible to adults, and adults' assessments may be biased by the child's academic performance or behaviors towards adults (Coie, 1985). Sociometric methods (e.g., peer ratings or nominations) provide important contextual information regarding the child's relative standing within his or her social group.

Sociometrics. Sociometric methods are used to obtain information on a student's social impact and preference. They also allow for the classification of a student's sociometric status (e.g., popular, rejected, neglected, or controversial) and are based on the assumption that the peer group may be reliable in providing information about social acceptability and impact. Indeed, peers are most often the primary recipients of a child's social overtures (or lack thereof), and they are most familiar with the social context in which social behaviors occur.

Sociometric methodologies appear to be very potent for assessing social impact and acceptance by one's social group (McConnell \& Odom, 1986).Several techniques are available, including positive and negative nomination techniques, and positive and negative rating scale methods. Rating scales used in conjunction with a positive nomination measure have also been recommended (McConnell \& Odom, 1986).

Self-reports. Along with adult and peer ratings, a student's self-perceptions regarding his or her social skillfulness and status are important. Students can provide accurate information regarding their own behaviors and perceptions (Witt, Cavell, Heffer, Carey, \& Martens, 1988), and self-reports provide important information that is not otherwise accessible to others (e.g., the child's thoughts and cognitions).

Behavior rating scales completed by the student provide helpful information regarding general social skills and behaviors. The SSRS (Gresham \& Elliott, 1990) contains a self-report scale for students at elementary and secondary lev- 
els. Ratings on critical items can be used to guide and structure a child interview, assess the child's interpretation of social situations, obtain direct and specific information to confirm or disconfirm hypotheses, and further narrow appropriate targets for intervention.

\section{"Best Practices" in Social Skills Assessment}

As with the evaluation of any childhood pathology, no single method or measure is sufficient in assessing social skills difficulties. Rather, a multisource, multimethod approach is necessary in obtaining a comprehensive picture of the extent, direction, and function of one's social skills and deficits. Teachers, peers, parents, and target students themselves should be included as sources of information. Likewise, given the differential nature and outcomes across assessment types, a variety of methods should be used (e.g., behavioral checklists and rating scales, sociometrics, direct observations, and self-reports). The purposes of assessment must be to continually generate and test hypotheses, identify specific excessive or deficient skill areas in need of remediation, and determine environmental conditions that may be utilized or modified to achieve the goals of intervention (Elliott et al., 1989).

Walker et al. (1986) described a multigating assessment procedure to identify students with both internalizing and externalizing behavior problems. The procedures consisted of three separate but interrelated stages or "gates." The first gate involved teachers' systematic evaluation of all children in their classrooms in terms of the extent to which they may be at risk for either externalizing or internalizing behavior disorders. The second gate also involved teacher ratings of students identified and ranked highest in gate one. Specifically, ratings were obtained on (a) a critical events index, and (b) a frequency index assessing multiple exemplars of externalizing and internalizing behavior disorders. The third gate involved direct observations of (a) academic engaged time recorded during independent seatwork periods, and (b) amount and quality of social behavior during recess periods on the playground. The target students' statuses on these measures were compared to age- and sex-appropriate normative levels to determine initial eligibility at this stage.

Although the Walker et al. (1986) system provides a relatively comprehensive assessment of select target students, some limitations are apparent. First, given the classwide ranking procedure, all students are given the opportunity to be selected for inclusion in formalized treatment. However, the specific behavioral skills in which target subjects are excessive or deficient are not identified. Second, although teachers can be reliable sources of social information, the gating procedure fails to solicit input from the recipients of target students' social overtures (e.g., the peer group). Third, self-perceptions of one's social skillfulness and effectiveness are not tapped, although these will undoubtedly impact one's readiness for and responsiveness to interventions. Finally, ratings of participant observers from environmental and social contexts other than the school (e.g., 
Table 2. Social Skills Training Strategies

1. Manipulation of Antecedents

A. Peer initiation strategies

B. Sociodramatics

C. Cooperative learning strategies

D. Ecological changes in environment

2. Manipulation of Consequences

A. Reinforcement-based procedures

B. Group contingencies

C. Peer-mediated reinforcement

3. Modeling-based Procedures
A. Symbolic modeling
B. Live modeling
C. Participant modeling

4. Cognitive-based Procedures
A. Coaching
B. Self-instruction, self-monitoring, self-reinforcement
C. Desensitization/flooding

Reproduced from: Elliott, S. N., Sheridan, S. M., \& Gresham, F. M. (1989). Assessing and treating social skills deficits: A case study for the scientist-practitioner. Journal of School Psychology, $27,197-222$.

parents in the home setting) are not obtained. A multigating assessment procedure implemented at a schoolwide level is necessary to address these limitations.

\section{Social Skills Interventions}

A number of effective interventions for social skills deficits have been identified. The range of procedures can be classified under three major headings: cognitive-behavioral, social learning, and operant conditioning procedures (Elliott et al., 1989). A brief overview of the procedures follows, and Table 2 reviews the three methods.

Cognitive-Behavioral Procedures. Cognitive-behavioral intervention procedures emphasize internal cognitions (thoughts, self-statements) and overt problem-solving abilities (Gresham, 1981). Two common cognitive-behavioral procedures include coaching and social problem solving. Coaching procedures involve direct verbal instructions and discussion as the major mediums of intervention (Oden \& Asher, 1977). A "coach" (teacher, parent, psychologist, or peer) first provides the student with specific rules or steps for a behavior. The coach and student then rehearse the steps, and the coach provides feedback about the child's performance. Coaching is often paired with other social skill intervention methods (such as modeling and positive reinforcement) to enhance its efficacy (Elliott et al., 1989).

Social problem-solving interventions focus on the cognitive processes associated with social competence and teach students the process of solving social 
problems (Sheridan \& Elliott, 1991). They generally attempt to teach a student to evaluate interpersonal problems logically and consider alternative, adaptive solutions. These procedures generally follow a specific problem-solving sequence and teach the student to analyze problems by asking a series of questions (e.g., "What is the problem?"; "What are my choices?"; "What are the consequences?"; "What is my best choice?"). Some programs also involve other cognitive strategies, such as role-taking. They can be used with an individual student or in groups or classroom settings. They are common components of several social skills curricula (Camp \& Bash, 1985; Spivack, Platt\& Shure, 1976). However, they do not teach discrete social skills and may be less effective with individuals exhibiting skill acquisition deficits.

Social Learning Procedures. According to social learning theory, social behaviors are acquired through observation and reinforcement. Modeling is an effective type of social learning procedure often used in social skills interventions (Gresham \& Nagle, 1980). This involves the use of films, audiotapes, videotapes, or live demonstrations of skills to be acquired. Live modeling of appropriate social behaviors can play a major role in learning and performing new social behaviors, especially when the model is similar to the target student and is reinforced for the prosocial behavior. Especially when paired with coaching procedures, modeling has been found to decrease rates of negative social interactions (Gresham \& Nagle, 1980).

Operant Procedures. Operant procedures focus on overt, discrete behaviors and surrounding antecedent/consequent events. Behavior change is most often achieved by social or material reinforcement of prosocial behaviors or in conjunction with the manipulation of antecedents and consequents (Elliott, Gresham, \& Heffer, 1987). All operant intervention procedures assume that a child has the skills within his or her repertoire but fails to perform them at desired levels. Thus, they are often used with cognitive-behavioral and social learning techniques to encourage utilization of the newly learned skills in nontreatment settings. Operant procedures can be classified according to conditions manipulated and contingencies employed (Gresham \& Elliott, 1990).

Manipulation of antecedent events in the environment set the stage for positive social interactions. Examples include prompting, cueing, and peer initiations. Cooperative learning strategies are effective procedures that require students to work together in completing academic tasks (Madden \& Slavin, 1983).

Manipulation of consequences include procedures designed to reinforce positive social behaviors. Techniques commonly used in social skills training programs include contingent social reinforcement and group contingencies (Elliott et al., 1987). In contingent social reinforcement, a teacher, parent, or other significant person reinforces appropriate social behavior socially or concretely. This procedure successfully increases rates of positive social behaviors, however, it requires a great deal of involvement and monitoring on the part of the teacher or parent. 
Group contingencies involve the application of consequences for group behavior (Litow \& Pumroy, 1975). These can be applied in various ways. For example, reinforcement can be applied contingent upon the behavior of selected children rather than an entire group (dependent group contingency), based on individual behavior independent of the behavior of others (independent group contingency), or based on the collective behavior of the group (interdependent group contingency). These procedures have been found to be effective for teaching social skills in classrooms (Elliott et al., 1987). Because students serve as behavior managers for themselves, group contingencies are also efficient in teacher time and effort.

Effectiveness of Social Skills Interventions. Schneider and Byrne (1985) reported the results of a major meta-analytic investigation that provided comparative effectiveness data for each of the major approaches to social skills interventions. From the extensive data provided by these researchers, it is clear that no single treatment approach or technique is uniformly effective. Rather, the success of social skill training procedures varies considerably among subjects and settings. However, some generalizations can be made. First, by comparing the mean effect sizes across all studies with all types of problems, Schneider and Byrne concluded that operant techniques were generally more effective than modeling and coaching procedures, which in turn were more effective than socialcognitive methods. Second, training tended to be more effective for withdrawn than for aggressive children. The difference was most pronounced in modeling studies, which were highly effective for withdrawn children. Coaching and operant techniques were found to be most effective for aggressive children. Schneider and Byrne suggested that problems of withdrawal may be more related to skill deficits and are alleviated by training in appropriate skills using such techniques as modeling. Aggression, on the other hand, may have more to do with the application of skills already acquired, with an inability to use these skills inappropriate situations. These children may benefit from coaching in the use of appropriate prosocial behaviors in problematic social situations, with contingent reinforcement to increase and maintain the use of these behaviors.

Although operant reinforcement procedures appear generally effective in increasing social interactive behaviors across groups, they may be insufficient in producing qualitative changes in a student's social competence. Operant procedures that direct treatment goals toward increasing social initiations or responses may be reinforcing peer interaction rates but not necessarily social skillfulness, peer acceptance, or qualitative aspects of the interaction (Walker, Greenwood, Hops, \& Todd, 1979). Likewise, operant procedures that reinforce only the demonstration of positive social behaviors may do little to decrease or extinguish negative social behaviors exhibited by aggressive students. Few operant studies have looked at qualitative deficits, and most have focused almost entirely on simply increasing peer interaction or prosocial behavior rates. There are many problems associated with this limited conceptualization of social behavior. First, simple reinforcement 
tends to overemphasize rate of interaction and disregards the quality of social interaction and responses. Second, operant procedures fail to provide direct instruction or training of more appropriate means of social interaction with which to replace inappropriate behaviors. Third, behavioral procedures have not been used in a way that leads to actual improvement in a child's peer relationships or social status (Sheridan \& Elliott, 1991). Thus, in practice most effective social skills interventions are combined procedures rather than any one used in isolation.

\section{"Best Practices" in Social Skills Interventions}

In practice, social skills programs are typically implemented to train a number of generic skills through a variety of procedures. For example, skills such as joining a game, starting conversations, following instructions, giving and receiving positive and negative feedback, and resisting peer pressure are often targeted in skill-based programs. Procedures such as direct instruction, modeling, coaching, behavioral rehearsal, operant conditioning, and social-cognitive procedures are typically used in some combination to teach and reinforce the acquisition and demonstration of appropriate social skills. However, as noted previously, several problems are apparent in the manner in which social skills training programs are implemented in practice. These include failure to consider the specific skill excesses or deficiencies exhibited by target students, and limited scope in the generalization of newly learned skills beyond the training setting.

Given the complexity of interpersonal behaviors demonstrated within social contexts, a combination of training techniques is recommended. The selection of procedures should be based on the nature of students' social skills difficulties (e.g., performance or skill deficits). In general, coaching, modeling, behavioral rehearsal, cueing, and positive reinforcement are potent components of social skills programs for students at risk. To maximize treatment effectiveness and increase potency of social skills interventions, these procedures should be implemented as a package and not in isolation.

To be truly effective, behaviors taught in any behavioral training program should generalize across skill opportunities, prompts, time, settings, individuals, and behaviors. Application of social skills outside the training setting and across untrained cues and opportunities rarely occurs naturally; rather, generalization must be programmed actively. Many procedures known as "generalization facilitators" (Michelson, Sugai, Wood, \& Kazdin, 1983; Stokes \& Baer, 1977) have been discussed to enhance generalization beyond the specific parameters of an intervention. In social skills training, generalization may be enhanced by teaching significant treatment agents within the natural environment procedures to prompt, model, and reinforce the utilization of a range of positive social skills (including those that are trained specifically and those that approximate target behaviors) in nontraining settings. In this way, environmental control is exerted beyond training settings and involves persons indigenous to the natural environment. Other examples of generalization facilitators include (a) teaching behav- 
iors that are likely to be reinforced and maintained by the natural environment (prosocial behaviors are an excellent example) ; (b) teaching a variety of alternative positive social responses; (c) making the training situation comparable to the natural environment by training across stimuli (e.g., skill opportunities, cues, persons, settings) that are common to the natural environment; (d) fading training consequences to approximate naturally occurring contingencies; and (e) including peers in training. Finally, formal follow-up data over time, collected via direct observations, multisource ratings, sociometrics, and self-reports are important both clinically and empirically.

\section{INTEGRATION OF RESEARCH AND BEST PRACTICE INTO A SCHOOLWIDE PROGRAM}

In the previous section, we reviewed relevant literature and discussed empirically based procedures that are effective in the assessment and treatment of social deficits in children. An ideal assessment $x$ treatment model would incorporate all of these empirically-derived techniques in the systematic delivery of services. However, several practical and logistical constraints evident in natural treatment environments (such as cost, resources, and time) preclude one's ability to develop and deliver a model of such complexity and comprehensiveness. Thus, it behooves practitioners to assess the most salient treatment needs within a given setting; identify practical, relevant, and valid treatment components to incorporate into a user-friendly package; and develop individual and program evaluation criteria. In other words, schoolwide social skills programs should be need- and resource-driven. The specific target skills, treatment components, and outcome measures will vary depending on setting; however, it is imperative that research findings and "best practices" be considered at all points of program development and implementation.

The social skills model presented below defines students at risk as those who have a decreased likelihood of completing school because of poor social skills, deficient problem-solving abilities, and/or underutilization of prosocial skills. Through such a program, future serious problems may be circumvented by addressing identified difficulties early (i.e., through secondary prevention procedures). The specific objectives of the model are to (a) conduct comprehensive student identification procedures to target need areas of a specifically high risk population; (b) implement schoolwide training procedures across a number of relevant social skills identified by teachers; (c) treat a specific subgroup of target students considered at highest risk for developing pervasive social problems; and (d) promote the transfer and generalization of target students' skills across settings and situations through the use of standardized cueing procedures.

\section{Comprehensive Assessment Procedures}

The program uses a multigating procedure, including behavioral checklists and rating scales, sociometric techniques, and self-reports in the initial identifica- 


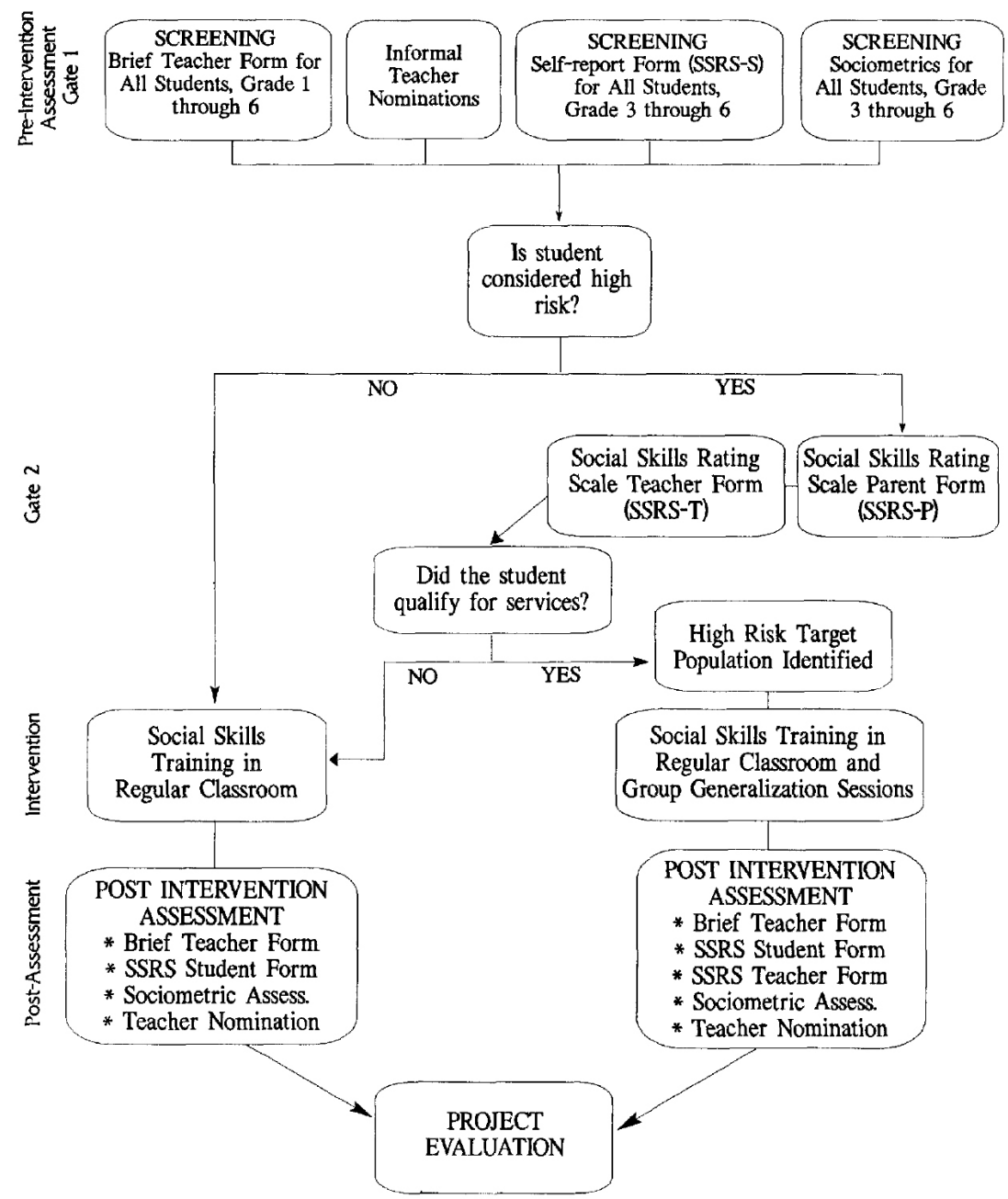

Figure 1. Multigating selection procedure: Flowchart of process for social skills project.

tion of at-risk students. Reports from parents, teachers, classmates, and individual students are included. Information is thus collected across methods, sources, and settings. Figure 1 presents the multigating student selection model used in this program.

A two-gate identification procedure (cf. Walker et al., 1986) is used to select a target group of students who are considered at risk for developing pervasive social problems. The first gate employs the Brief Teacher Form (explained below) completed by classroom teachers for all students in grades 1 though 6 , the SSRS-S (the self-report portion of the Social Skills Rating Scales; Gresham \&Elliott, 1990), and a sociometric measure for students in grades 3 through 6. Stu- 
Table 3. Items from Brief Teacher Form

1. Controls temper in conflict situations with others.

2. Compromises in conflict situations by changing own idea to reach agreement.

3. Is able to receive criticism well.

4. Initiates conversations appropriately with peers.

5. Disturbs ongoing activities.

6. Lets friends know he/she likes them by telling or showing them.

7. Asks permission before using other people's things.

8. Appropriately tells you when he/she thinks you have treated him/her unfairly.

9. Can accept compliments or praise from friends.

10. Gets angry easily.

11. Compliments or praises others when appropriate.

12. Tries to understand how others feel when they are angry, sad, or upset.

dents who score in the lower one-fifth (20th percentile) from each grade on either SSRS-S, the sociometric technique, or the Brief Teacher Form are further assessed via the second gate of the identification procedure.

In the second gate, the SSRS-Teacher Form (SSRS-T; Gresham \& Elliott, 1990 ) is completed by classroom teachers. Students who rate below the 50th percentile for each grade on the SSRS-T (i.e., approximately half of those students identified by the first gate) qualify for extensive small group services. A description of each of the assessment techniques follows, with their sequential administration outlined in Figure 1.

Rating Scales. Various levels of behavioral checklists and rating scales are used in the program to assess general social skills of entire classrooms of students. First, the Brief Teacher Form is used to obtain information from teachers on all students in a school. The Brief Teacher Form uses a 12-item questionnaire that assesses critical items from the student and teacher forms of the SSRS. The forms are completed by all regular classroom teachers on every student in the school. The teacher rates the frequency of each student behavior on a 3-point scale (rarely [0], sometimes [1], very often [2]). The questionnaire also asks the student's ethnicity, grade, sex, and whether the student is classified to receive special services. The Brief Teacher Form is included in Table 3.

Items on the Brief Teacher Form were selected by a committee of school personnel and the social skills project team. At the beginning of the project year, committee members nominated behaviors of critical concern. These items were submitted to the project team, who further operationalized them by selecting corresponding items from the SSRS. These items were resubmitted to the school committee to determine if the critical concerns had been addressed.

The SSRS (Gresham \& Elliott, 1990) is a standardized rating scale designed to screen and classify children who may have significant social behavior problems. Separate forms for parents, teachers, and students are available, and there are separate instruments for preschool, elementary, and secondary students. In the schoolwide program, the SSRS-Teacher Form (SSRS-T) and 
Self-Report Form (SSRS-S) are used. At the second gate of the screening process, the SSRS-Parent Form (SSRS-P) is administered to further narrow the final target group.

At the elementary level, the SSRS-T, SSRS-S, and SSRS-P contain 30, 34, and 38 social skills items, respectively. Each item on the SSRS relates to a specific social behavior and is rated both in terms of how frequently it occurs (Never, Sometimes, or Very Often) and how important it is to the individual completing the scale (Not Important, Important, Critical). Factor analyses of the SSRS revealed the factors of Cooperation, Assertion, and Self-Control across all scales. The Student and Parent Reports include additional factors of Empathy and Responsibility, respectively (Clark, Gresham, \& Elliott, 1985; Gresham, Elliott,\& Black, 1987). Three broad-band problem behavior domains (Internalizing, Externalizing, and Hyperactivity) are included on the Teacher and Parent Reports, with an Academic Competence scale also on the Teacher Form.

Sociometrics. Students in grades 3 through 6 are asked to select five classmates based on whether they would choose to work with them on a class project, play with them at school, or not choose to play with them at school. Students are instructed that there are no right or wrong answers to the survey items. They are also encouraged to keep their answers private and avoid later conversations with their peers about their responses. To avoid forced inflation of negative nominations, students are instructed to list no more than five classmates with whom they would choose not to play or work. It should be emphasized that students may list fewer than five peers and that they are not required to list any peers on the negative nomination items.

The sociometric data are compiled by using a class roster and tallying the number of nominations each student receives for each of the survey items. Items can be weighted to assist in the identification process, depending on the focus of the social skills intervention. For example, to identify rejected students, negative nominations are weighted and contribute to a composite score. Information can also be used from the positive nominations to help identify popular or respected peers, who can then be used as positive peer models or helpers in the training.

Students who score in the lower one-fifth (20th percentile) from each grade on the sociometric technique are further assessed via the second gate of the identification procedure. This typically amounts to identifying three to five students per classroom, many of whom may also be identified by the other first-gate screening procedures (e.g., Brief Teacher Report, SSRS-S).

Direct Observation. During recess and in small group training activities, independent observers record selected behaviors of target and comparison students. Each target and selected comparison student is observed weekly. Observers utilize a 15 -second observe, 5 -second record partial interval observational procedure. For practical purposes, playground observation sessions are 10 minutes in length. To increase reliability in observations, the observation and recording intervals are signaled by an audiotape message delivered through headphones of a personal stereo cassette player. 
Table 4. Outline of In-service Objectives

Staff In-Service I:
A. Program Rationale
B. Purpose and Objectives
C. Program Staff
D. General Procedures
E. Assessment and Selection Procedures
F. Project Timeline
G. Setting Realistic Expectations

Staff In-Service II:
A. Classroom-based Social Skills Groups: Steps and Components
B. Video Clips C. Small Group Activities: Steps and Components
D. Video Clips
E. Prompting Skill Utilization: Flowchart
F. Video Clips

Observers are trained to criteria using naturalistic playground situations depicted on videotape. Twenty percent of all observations are conducted by two observers to assess the reliability of observational data. The observers use a single cassette player and audiotape equipped with a split earphone. Observers are not informed as to whether students are targeted because of poor social skills or included as comparison students.

\section{Staff Training}

Comprehensive training of all school staff is considered an important part of the schoolwide social skills training project. This training is conducted in two broad phases. The first phase involves a two-part in-service, wherein all school staff learn the general purposes and procedures of the program. The second phase of training involves two "booster sessions," wherein staff are reconvened in two large groups to discuss basic operations of the program after it has been in effect for approximately 4 and 6 months.

Training Phase I: In-services. The first phase of training is conducted early in the school year, as the initial screening and identification procedures are being implemented. The in-service training is conducted in two 60-minute sessions. Each session consists of small groups of approximately ten staff members to facilitate discussion and communication regarding program details. Because the social skills program is intended to permeate throughout all aspects of the school day, all classroom teachers, support teaching staff (e.g., resource, Chapter I, bilingual, speech-language), and other staff in the school (e.g., lunchroom and playground monitors, office staff) are involved in the in-service training. Objectives of each of the in-services are provided in Table 4.

The purpose of the first in-service is to inform staff of the general purposes and procedures of the social skills program, including their roles in its implemen- 
tation. A general information meeting is held, during which the school psychologist and other individuals responsible for overseeing the program review the purpose, objectives, and general procedures. The identification process is also reviewed at this time, and classroom teachers are provided with the nomination forms for the first level of screening.

Whereas the first in-service is primarily informational, the second session is skill-based. Specifically, school staff are instructed in the correct procedures for implementing classroom-based training, small-group activities, and generalization practices (i.e., prompting, modeling, and reinforcement outside of training sessions). Videotaped demonstrations of each of these procedures are included to provide training models and stimulate discussion among participants.

Training Phase II: Booster Sessions. The second general phase of staff training (i.e., booster sessions) is conducted after the program has been in effect for a number of months. Booster sessions are held in larger groups of approximately 15 to 20 individuals to stimulate discussion on a number of issues. As with training phase I, this phase is conducted in two parts. The purposes of the first booster session are to reconvene as a school staff to discuss program operations and invite feedback regarding salient program issues as experienced by its participants. Troubleshooting of difficulties encountered in implementing the program and brainstorming of alternative practices are invited during the first booster session.

The purposes of the second booster session, conducted toward the end of the school year, are to provide closure on the formal social skills program, review end-of-year assessment procedures, and discuss implementation issues for the upcoming academic year. It is hoped that by this time, teachers and other school staff have internalized the program sufficiently to conduct it independent of additional assistance provided by district resources.

\section{Classroom-based Skills Training}

In the schoolwide social skills treatment program, the entire school (grades 1 through 6) are involved in classroom-based training. Involvement of all school personnel is encouraged at this level. For example, an administrator, social worker, special education teacher, or other staff person can assist classroom teachers in the implementation of classroom-based sessions. The lesson skills sequence and in-class training protocol, adapted from the work of McGinnis and Goldstein (1984) and Schumaker, Hazel, and Pederson (1983), are listed in Table 5 .

The classroom-based training involves one half-hour lesson conducted weekly in each regular education classroom. Classroom teachers participate in the sessions to help teach target skills, monitor and provide feedback during roleplays, gain information on skills being targeted, and enhance skill transfer and generalization outside of the training sessions. In grades 3 through 6 , all students form pairs to practice the role-play exercises. Students practice the skill steps while the trainer and the teacher observe this practice and provide behavioral feedback (i.e., prompts, instruction, and reinforcement). Roles are then switched 
Table 5. Classroom-based Social Skills Training Procedures
Session Format
1. Review of previous weeks social skill
2. Introduction of new skill (modeling, discussion, rationale)
3. Overview of skill steps
4. Modeling of skill (examples, nonexamples, random)
5. Role-playing
6. Summary
7. Generalization homework assignment
Lesson Skills Sequence
1. Body basics of assertiveness
2. Following instructions
3. Problem solving 4. Decision making
5. Controlling your temper
6. Aggression replacement
7. "I" messages
8. Giving positive feedback
9. Accepting positive feedback
10. Asking permission/Making requests
11. Feelings
12. Body language
13. Accepting negative feedback/Teasing
14. Giving negative feedback
15. Initiating conversation/Communication skills
16. Negotiation/Compromise

to allow each student to practice the target skill. In grades 1 and 2, two students perform the role-play exercises in front of the class, and the trainer and teacher guide the other students in providing feedback.

\section{Small Group Sessions}

To provide more intensive skill training to students considered at highest risk (i.e., students who meet criterion at the second level of the gating procedure), approximately 6 to 8 students from each grade are involved in weekly activity sessions. The activities (e.g., basketball, four-square) provide opportunities for the students to practice skills and for the trainers to reinforce the use of these skills. Specifically, trainers provide positive and corrective feedback to students and use guided practice when necessary. An outline of the procedural details of small group activities is included in Table 6.

Two nontarget students at each grade level are included in small group sessions to help model appropriate behaviors and also serve as comparison students in assessing the impact of the treatment on target students. These model students (nonreferred and uninformed) are selected on the basis of average scores on the Brief Teacher and SSRS-T forms. 
Table 6. Outline for Small Group Activities

1. Explain/review group rules.

2. Discuss current skill covered in week's classroom session.

3. Conduct role-plays and discussion of how skills were applied at school and at home.

4. Review specific skills appropriate for recreational activity.

5. Introduce group activity for the day.

6 . Review rules for the activity.

7. Conduct activity providing positive and corrective feedback and guided practice.

8. Summarize and get feedback on group's overall performance.

\section{Skill Generalization and Reinforcement}

Several procedures are embedded within the program to enhance generalization and transfer of classroom-based and small group lessons. First, all school staff are trained in systematic generalization procedures (see Figure 2). Second, a token reinforcement program is initiated by the school in cooperation with the PTA. Students are given tickets (tokens) when they are observed exhibiting one of the social skills spontaneously or when prompted by school staff. Tokens are redeemed weekly at a school store operated by the PTA. An assortment of edibles, education items, and toys are available in the store.

Generalization to the home setting is also promoted and assessed in the schoolwide program. This occurs through the use of a home practice report. First, the report is used to inform parents of the social skills training that takes place in the classroom by providing a record of the skill and its steps. Second, it encourages parent and student practice of skills presented in the classroom-based sessions. Specifically, parents are asked to report the days on which the student practices the skill, whether the student's social interactions seem to be "improving, about the same, or getting worse," and other comments on their use of social skills at home. Parents and students are also asked to sign the report.

\section{Treatment Integrity and Acceptability}

Treatment Integrity. Integrity of the various program components is assessed to ensure that the program procedures are implemented as intended. The Treatment Integrity Form is a 10-item scale developed to assess trainers' compliance with the schoolwide teaching procedures. Trained observers observe classroombased social skills training sessions and rate individual trainers on their adherence to the standard training protocol (see Table 5).

Treatment Acceptability. Acceptability of the standard social skills program and its various components is assessed to obtain feedback from consumers (i.e., teachers and students). The Teacher Satisfaction Form is an 8-item, 7-point Likert scale designed to determine classroom teachers' satisfaction with the social skills project. The items assess the program components and the presentation of skills. The items address (1) usefulness of material presented to students; (2) ap- 


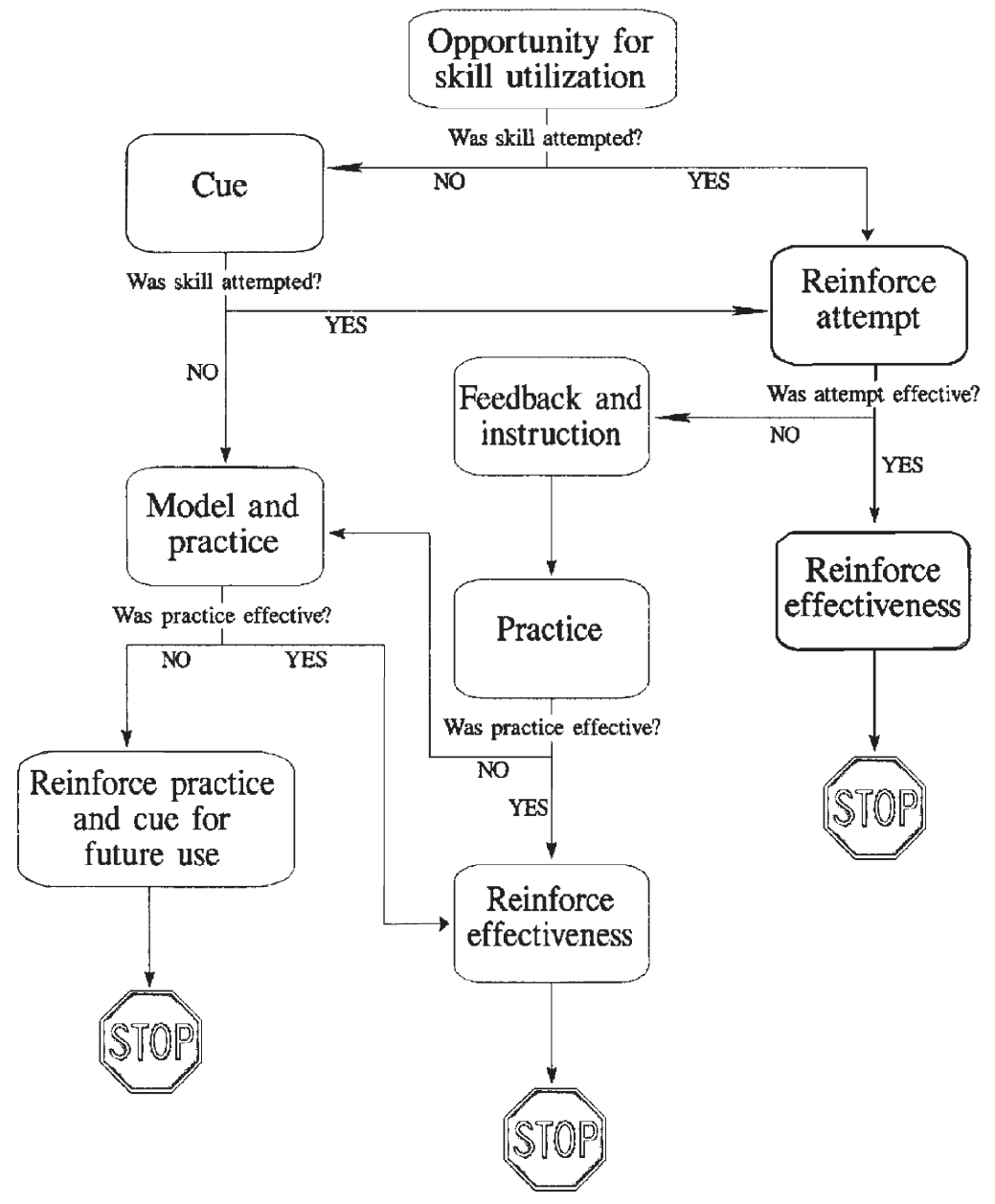

Figure 2. Generalization flowchart for social skills.

propriateness of level of difficulty; (3) pace of presentation; (4) number of new ideas/skills presented; (5) overall recommendation of program to other teachers; (6) lecturing/presentation skills; (7) discussion/role-play skills; and (8) instructor's overall teaching effectiveness. There is also space for comments on the form. Teachers complete the form at the termination of the social skills program.

The Student Satisfaction Form is a 7-item form designed to gather information about students' satisfaction with the program. It is completed after the final classroom-based social skills session. The form has five 3-point Likert items that assess (1) interest level of the social skills classes; (2) knowledge of skills by instructor; (3) importance of the skills learned; (4) use of skills in daily life; and (5) recommendation of social skills program to peers. Two open-ended questions are also included, which assess perceptions of the "best" and "worst" parts of the classes. 
Table 7. Evaluation Components

\begin{tabular}{lcc}
\hline Measures & Schoolwide & Target Group \\
\hline Child Focus & & \\
$\quad$ SSRS-SR & $\mathrm{X}^{\mathrm{a}}$ & $\mathrm{X}^{\mathrm{a}}$ \\
$\quad$ SSRS-TR & & $\mathrm{X}^{\mathrm{a}}$ \\
$\quad$ SSRS-PR & $\mathrm{X}^{\mathrm{a}}$ & \\
Brief Teacher Form & $\mathrm{X}^{\mathrm{a}}$ & $\mathrm{X}^{\mathrm{b}}$ \\
Sociometric & & \\
Direct Observation & $\mathrm{X}^{\mathrm{b}}$ & $\mathrm{X}^{\mathrm{b}}$ \\
Home Practice Report & & \\
Program Focus & $\mathrm{X}^{\mathrm{b}}$ & \\
$\quad$ Treatment Integrity & & \\
Consumer Satisfaction & $\mathrm{X}^{\mathrm{c}}$ & \\
$\quad$ Teacher & $\mathrm{X}^{\mathrm{c}}$ & \\
Students & $\mathrm{X}^{\mathrm{b}}$ & \\
Teacher Report of f/u Practice Sessions & & \\
\hline
\end{tabular}

a Pretreatment and posttreatment data collection

${ }^{\mathrm{b}}$ Continuous data collection

c Posttreatment data collection only

Note: Target group students also participate in all schoolwide components.

\section{Evaluation Measures}

As with any comprehensive intervention program, evaluation procedures are important to document that desired effects are being attained. Likewise, information regarding consumer satisfaction and treatment integrity are important. Several procedures are used to meet these objectives in the social skills program. These include direct observations, behavioral checklists and rating scales, sociometric techniques, and self-reports. An overview of the evaluation components is presented in Table 7.

Direct observations of target students during recess are conducted to evaluate effectiveness and maintenance of treatment. Postintervention assessment also includes repeating the screening and assessment instruments (i.e., Brief Teacher Form, SSRS-T, SSRS-S, SSRS-P, sociometrics). Thus, pre- to postintervention comparisons are possible, and changes in students' social skills can be reported descriptively.

Home practice reports are also examined to provide one source of information regarding generalization of skill utilization to the home setting. On these forms, parents report student home practices of target skills and provide global information on improvements in child social interactions. Treatment integrity observation ratings are used to determine the percentage of teaching behaviors that 
are performed correctly. Likewise, consumer satisfaction measures are obtained from teachers and students to determine their satisfaction with the procedures. Teacher satisfaction is assessed with the Teacher Satisfaction Form and student satisfaction is assessed with the Student Satisfaction Form.

\section{SUMMARY AND RESEARCH CONSIDERATIONS}

This article reports a "package" model and procedures for implementing a schoolwide social skills training program. The package is offered as a starting point and includes important components gleaned from the literature. However, it has not been validated independently, nor is it the ideal or gold standard package for developing or implementing a social skills training program. An ideal model often does not meet the practicing clinician's or researcher's pragmatic requirements and restrictions. Therefore, some practitioners and researchers may choose to drop or alter some components of the present package or add some of the components discussed below to suit their particular clinical/research needs. We will now review some of these components.

As noted, one of the next steps is to socially validate the efficacy of the presented package. First, the merit of this program should be tested experimentally. For example, single-subject designs (e.g., multiple baseline) can be used to test its efficacy with specific students at risk. Likewise, group designs and component analysis can be used to obtain credible outcome information on the package as a whole or for specific aspects of training (e.g., classroom-based sessions, small group activities).

While we believe that the explicit efforts to transfer and generalize prosocial skills is a unique dimension of this model, this assertion should be tested empirically. Individual components of the package might also be investigated, with consideration to determining their efficacy. For example, pretreatment direct observation data (e.g., student behavior during recess) could be gathered to establish the frequency of prosocial and antisocial behaviors. This baseline information could be used clinically to help identify the skills to be addressed in training, and coupled with continued direct observation, used experimentally for determining intervention effectiveness. Direct observation data could also be obtained during the last one or two months of the school year to gauge behavior maintenance. For this information to be useful, researchers and clinicians are advised to ensure that observers be trained rigorously and their reliability be monitored systematically.

Individual skills included in training, as well as their order of presentation, should be evaluated to determine their role in and contribution to the overall program. "Keystone" skills (i.e., those identified empirically as central to social competency) can be presented first, around which all the other skills are taught. For example, general skills of self-control or problem solving might be demonstrated to be prerequisite to a number of more specific behaviors such as controlling anger or accepting losing. In any case, controlled observations of competent 
social behaviors should be subjected to systematic task analyses to determine a core set of keystone (i.e., focal) skills.

Because of the limitations on practitioner time, alternatives for implementing the schoolwide training program might be considered where independent funding (e.g., a small district grant or reassignment of professionals) is not available. Some of the options include arranging reinforcement contingencies to encourage teachers and other school staff to take more ownership and responsibility for the program through teacher reinforcement procedures, using peer social skills tutors, and enlisting parent volunteers. Volunteers and peer tutors could be trained to help conduct the classroom-based and small group sessions in addition to running a reinforcement store where students could redeem tokens earned by demonstrating prosocial skills. The school psychologist can play a critical consultant role when any of these adaptations are employed.

Parent involvement might be strengthened by holding open meetings at the beginning of and intermittently throughout the project. These meetings could be used to develop a contingent of parent volunteers, in addition to teaching them how to use the generalization procedures (Figure 2) in their daily parenting activities.

After careful and sufficient attention to the procedures designed to encourage acquisition of prosocial skills, it may be necessary to consider adding a response cost procedure for antisocial behaviors if examination of the data indicates that the frequency of these behaviors continues at an unacceptable rate. An example of this would be to fine (i.e., use a response-cost procedure) students who exhibit antisocial behaviors in the school or at recess. Before this type of procedure is considered, however, we recommend that the training and reinforcement procedures be investigated thoroughly over a sufficient time period. Alternatives to antisocial behavior should be trained extensively and supported by the environment before response-cost or punishment procedures are used (e.g., Harris \& Ersner-Hershfield, 1978).

With careful planning, a high level of teacher cooperation and commitment, and creative use of parent and student volunteers, a social skills training program can combine both intervention and research components. We propose that applying best practices in a package model will provide useful information that can be applied across a broad range of skill settings.

\section{References}

Asher, S. R., Markell, R. A., \& Hymel, S. (1981). Identifying children at risk in peer relations: A critique of the rate-of-interaction approach to assessment. Child Development, 52, $1239-1245$.

Black, D. D., Downs, J., Bastien, J., Brown, L. J., \& Wells, P. (1987). Social skills in the school. Omaha, NE: Boys Town.

Botvin, G. J. (1983). Life skills training: Teacher's manual. New York: Smithfield Press.

Camp, B. W., \& Bash, M. A. S. (1985). Think aloud classroom program, Grades 5-6. Champaign, IL: Research Press. 
Cartledge, G., \& Milburn, J. (1986). Teaching social skills to children: Innovative approaches (2nd ed.). New York: Pergamon.

Clark, L., Gresham, F. M., \& Elliott, S. N. (1985). Development and validation of a social skills assessment measure: The TROSS-C. Journal of Psychoeducational Assessment, 4, $347-356$.

Coie, J. D. (1985). Fitting social skills intervention to the target group. In B. H. Schneider, K. H. Rubin, \& J. E. Ledingham (Eds.), Children's peer relations: Issues in assessment and intervention (pp. 141-156). New York: Springer-Verlag.

Coie, J. D., \& Dodge, K. A. (1983). Continuity of children's social status: A five-year longitudinal study. Merrill-Palmer Quarterly, 29, 261-282.

Cowen, E. L., Pederson, A., Babigan, H., Izzo, L., \& Trost, N. (1973). Long term follow-up of early detected vulnerable children. Journal of Consulting and Clinical Psychology, 41, 438-446.

DeLeon, D. (1986). The prevention of mental-emotional disabilities: Report of the National Mental Health Association Commission on the Prevention of Mental-Emotional Disabilities. Alexandria, VA: NMHA.

Dougherty, A. M. (1988). Children's mental health problems and services: Current federal efforts and policy implications. American Psychologist, 43, 808-812.

Elias, M. J., \& Branden, L. R. (1988). Primary prevention of behavioral and emotional problems in school-aged populations. School Psychology Review, 17, 581 -592.

Elliott, S. N., \& Gresham, F. M. (1992). Social skills intervention guide. Circle Pines, MN: AGS.

Elliott, S. N., Gresham, F. M., \& Heffer, R. W. (1987). Social skills interventions. In C. A. Maher \& J. E. Zins (Eds.), Psychoeducational assessment in schools (pp. 141-159). New York: Pergamon.

Elliott, S. N., Sheridan, S. M., \& Gresham, F. M. (1989). Assessing and treating social skill deficits: A case study for the scientist-practitioner. Journal of School Psychology, 27, 197-222.

Forman, S. G., \& Linney, J. A. (1988). School-based prevention of adolescent substance abuse: Programs, implementation, and future directions. School Psychology Review, 17, 550-558.

Gresham, F. M. (1981). Social skills training with handicapped children: A review. Review of Educational Research, 51, 139-176.

Gresham, F. ML, \& Elliott, S. N. (1990). Social skills rating system: Manual. Circle Pines, MN: American Guidance Service.

Gresham, F. M., Elliott, S. N., \& Black, F. L. (1987). Factor structure replication and bias investigation of the teacher rating of social skills. Journal of School Psychology, 25, 81-92.

Gresham, F. M., \& Nagle, R. J. (1980). Social skills training with children: Responsiveness to modeling and coaching as a function of peer orientation. Journal of Consulting and Clinical Psychology, 48, 718-729.

Harris, S. L., \& Ersner-Hershfield, R. (1978). Behavioral suppression of seriously disruptive behavior in psychotic and retarded patients: A review of punishment and its alternatives. Psychological Bulletin, 85, 1352-1375.

Kazdin, A. E. (1977). Assessing the clinical or applied importance of behavior change through social validation. Behavior Modification, 1, 427-451.

Litow, L., \& Pumroy, D. K. (1975). A brief review of classroom group-oriented contingencies. Journal of Applied Behavior Analysis, 8, 341-347.

Madden, N. A., \& Slavin, R. E. (1983). Mainstreaming students with mild handicaps: Academic and social outcomes. Review of Educational Research, 53, 519-569. 
McConnell, S. R., \& Odom, S. L. (1986). Sociometrics: Peer-referenced measures and the assessment of social competence. In P. S. Strain, M. J. Guralnick, \& H. M. Walker (Eds.), Children's social behavior: Development, assessment, and modification (pp. 215-285). New York: Academic Press.

McGinnis, E., \& Goldstein, A. P. (1984). Skillstreaming the elementary school child: A guide for teaching prosocial skills. Champaign, IL: Research Press.

Michelson, L., Sugai, D. P., Wood, R. P., \& Kazdin, A. E. (1983). Social skills assessment and training with children: An empirically based approach. New York: Plenum.

Oden, S., \& Asher, S. R. (1977). Coaching children in social skills for friendship making. Child Development, 43, 495-506.

Parker, J. G., \& Asher, S. R. (1987). Peer relations and later personal adjustment: Are low-accepted children at risk? Psychological Bulletin, 102, 357-389.

Schneider, B. H., \& Byrne, B. M. (1985). Children's social skills: A meta-analysis. In B. H. Schneider, K. H. Rubin, \& J. E. Ledingham (Eds.), Children's peer relations: Issues in assessment and intervention (pp. 175-192). New York: Springer-Verlag.

Schumaker, J., Hazel, S., \& Pederson, C. (1983). Social skills for daily living: A curriculum. Circle Pines, MN: American Guidance Service.

Sheridan, S. M., \& Elliott, S. N. (1991). Behavioral consultation as a process for linking the assessment and treatment of social skills. Journal of Educational and Psychological Consultation, 2, 151-173.

Spivack, G., Platt, J. J., \& Shure, M. B. (1976). The problem-solving approach to adjustment. San Francisco: Jossey-Bass.

Stokes, T., \& Baer, D. (1977). An implicit technology of generalization. Journal of Applied Behavior Analysis, 19, 349-367.

Walker, H. M., Greenwood, C. R., Hops, H., \& Todd, N. M. (1979). Differential effects of reinforcing topographic components of social interaction: Analysis and replication. Behavior Modification, 3, 291-321.

Walker, H., \& McConnell, S. (1988). Walker-McConnell scale of social competence and school adjustment. Austin, TX: PRO-ED.

Walker, H. M., Severson, H., Stiller, B., Williams, G., Haring, N., Shinn, M., \& Todis, B. (1986).Systematic screening of pupils in the elementary age range at risk for behavior disorders: Development and trial testing of a multiple gating model. Remedial and Special Education, 9 (3), 8-14.

Witt, J. C, Cavell, T. A., Heffer, R. W, Carey, M. P., \& Martens, B. K. (1988). Child self-report: Interviewing techniques and rating scales. In E. S. Shapiro \& T. R. Kratochwill (Eds.), Behavioral assessment in schools: Conceptual foundations and practical applications (pp. 384-454). New York: Guilford. 